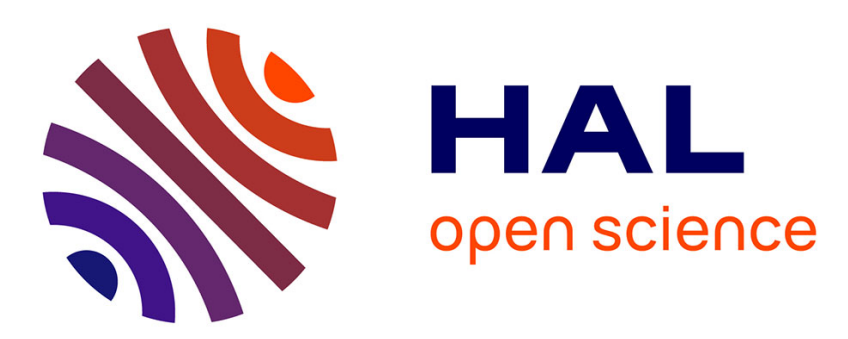

\title{
Ground deformation and gravity variations modelled from present-day ice thinning in the vicinity of glaciers
} Anthony Memin, Y. Rogister, J. Hinderer, M. Llubes, E. Berthier, J.-P. Boy

\section{To cite this version:}

Anthony Memin, Y. Rogister, J. Hinderer, M. Llubes, E. Berthier, et al.. Ground deformation and gravity variations modelled from present-day ice thinning in the vicinity of glaciers. Journal of Geodynamics, 2009, 48 (3-5), pp.195. 10.1016/j.jog.2009.09.006 . hal-00594427

\section{HAL Id: hal-00594427 \\ https://hal.science/hal-00594427}

Submitted on 20 May 2011

HAL is a multi-disciplinary open access archive for the deposit and dissemination of scientific research documents, whether they are published or not. The documents may come from teaching and research institutions in France or abroad, or from public or private research centers.
L'archive ouverte pluridisciplinaire $\mathbf{H A L}$, est destinée au dépôt et à la diffusion de documents scientifiques de niveau recherche, publiés ou non, émanant des établissements d'enseignement et de recherche français ou étrangers, des laboratoires publics ou privés. 


\section{Accepted Manuscript}

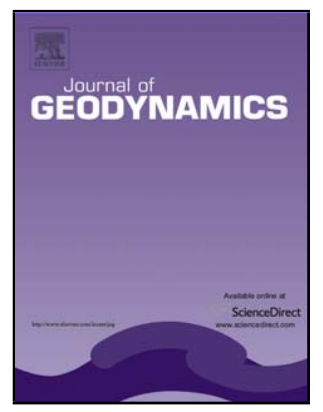

Title: Ground deformation and gravity variations modelled from present-day ice thinning in the vicinity of glaciers

Authors: A. Memin, Y. Rogister, J. Hinderer, M. Llubes, E. Berthier, J.-P. Boy

PII: $\quad$ S0264-3707(09)00073-8

DOI: $\quad$ doi:10.1016/j.jog.2009.09.006

Reference: $\quad$ GEOD 900

To appear in: $\quad$ Journal of Geodynamics

Please cite this article as: Memin, A., Rogister, Y., Hinderer, J., Llubes, M., Berthier, E., Boy, J.-P., Ground deformation and gravity variations modelled from present-day ice thinning in the vicinity of glaciers, Journal of Geodynamics (2008), doi:10.1016/j.jog.2009.09.006

This is a PDF file of an unedited manuscript that has been accepted for publication. As a service to our customers we are providing this early version of the manuscript. The manuscript will undergo copyediting, typesetting, and review of the resulting proof before it is published in its final form. Please note that during the production process errors may be discovered which could affect the content, and all legal disclaimers that apply to the journal pertain. 


\title{
Ground deformation and gravity variations modelled from present-day ice thinning in the vicinity of glaciers
}

\author{
A. MEMIN*,a , Y. ROGISTER ${ }^{\mathrm{a}}$, J. HINDERER ${ }^{\mathrm{a}}$, M. LLUBES $^{\mathrm{b}}$, E. \\ BERTHIER $^{\mathrm{b}, \mathrm{c}}$, J.-P. BOY ${ }^{\mathrm{a}}$ \\ a IPGS-EOST, CNRS/UdS, UMR 7516, 5 rue René Descartes, 67084 Strasbourg Cedex, \\ France \\ ${ }^{b}$ Université de Toulouse; UPS (OMP-PCA); LEGOS; 14 Av. Edouard Belin, 31400 \\ Toulouse, France \\ ${ }^{c}$ CNRS; LEGOS; 14 Avenue Ed. Belin, 31400 Toulouse, France.
}

\begin{abstract}
The solid Earth deforms because of post-glacial rebound due to the viscous relaxation following the last deglaciation but also because of present-day elastic deformation induced by ice thinning. In this paper, we compute elastic loading Green's function associated to the tilt of the ground in the vicinity of glaciers using a Love number formalism for a stratified non-rotating spherical Earth model. We compare this global approach with the plane approximation in terms of height, gravity and tilt changes as a function of the distance from the measurement point to the load. We find that Green's functions for the vertical displacement (resp. horizontal displacement, elastic part of the tilt) agree to within $1 \%$ up to $\sim 400 \mathrm{~m}$ (resp. $2 \mathrm{~km}, 5 \mathrm{~km}$ ) from the glaciers. Two specific cases of ice thinning are considered:1/ the alpine glaciers of the Mont Blanc region (France) where ice-thickness variations are derived from differential digital elevation model analysis for the period 1979-2003; 2/ the
\end{abstract}

*Tel: + 333 90240034, Fax: +33 390240291

Email address: anthony.memin@eost.u-strasbg.fr (A. MEMIN) 
Svalbard (Norway) glaciers by considering the ice model SVAL. We show that the rates of ground tilt are well above the limit of detection of up-todate long base hydrostatic tiltmeters, which, if installed next to the glaciers, could be used to monitor the time evolution of ice thinning. We also show that the topography has a strong influence on the gravity variations near the glaciers.

Key words: ground tilt, gravity variations, elastic deformations,

present-day ice thinning

\section{Introduction}

Since the end of the little ice age, most ice masses on Earth have experienced a reduction of their volume (Vincent et al., 2005; Rabatel et al., 2008) and, recently, an acceleration of the ice-thinning rates has been observed over many ice-covered areas (Meier et al., 2007). Rapid ice thinning has been reported on the Greenland (Howat et al., 2007; Stearns and Hamilton, 2007; Barletta et al., 2008; Slobbe et al., 2009) and the West Antarctic ice sheets (Cazenave, 2006; Rignot et al., 2008; Barletta et al., 2008; Horwath and Dietrich, 2009), large icefields in Patagonia and Alaska (Arendt et al., 2002; Rignot et al., 2003; Chen et al., 2006, 2007), ice caps in Iceland (Magnùsson et al., 2005), as well as on mountain glaciers, for instance in the Alps (Berthier et al., 2004), Svalbard (Kohler et al., 2007) or Himalaya (Berthier et al., 2007). Ice-thinning rates range from a few tenths of centimetres per year, in Svalbard for instance (Kohler et al., 2007), to several meters per year such as in the French Alps (Berthier et al., 2004) and can reach more than ten meters per year in Greenland (Howat et al., 2007; Stearns and 
Hamilton, 2007).

Past and present-day ice thinning induce a deformation at the Earth surface that has been observed in GPS and gravity measurements close to the shrinking ice bodies (Pagli et al., 2007; Sato et al., 2006; Sjöberg et al., 2004; Khan et al., 2007). Knowing the current ice-thickness variations, from differential analysis of digital elevation models (DEMs), one can estimate the ground deformations and the gravity changes. Using the World Glacier Inventory database, Barletta et al. (2006) have shown that, in the European Alps, the highest elastic rebound $(0.9 \mathrm{~mm} / \mathrm{yr})$ due to current ice melting is located in the Mont Blanc area. The reduction in ice volume also induces a tilt of the ground that, close enough to the glaciers, should be detectable by modern tiltmeters, which are already used for monitoring small deformation of the ground due to hydrological loads (e.g. Rerolle et al., 2006) or ocean tide loading (e.g. Llubes et al., 2008).

In this paper, we investigate the solid Earth deformation induced by the thinning of three glaciers in the Mont Blanc massif (Mer de Glace, Talèfre, Leschaux) and in Svalbard (Norway) in the Arctic. In the Alps, we consider ice-thinning rates derived from differential DEMs that provide a 24 year-long evolution of the ice thickness (Berthier et al., 2004) whereas in Svalbard our analysis is based on the SVAL model (Hagedoorn and Wolf, 2003). We compute the subsequent Earth deformation, which includes the displacement of the ground and gravity variation, for both a spherical elastic Earth model and a homogeneous elastic half-space. To do so, we convolve Green's functions (Farrell, 1972) obtained for these two models with the variation of ice thickness. A comparison between Green's functions of the spherical and half- 
space models confirms that the half-space model is a valid approximation at a local scale (i.e. for distances less than 1-10 km). We also model the variation of the tilt of the ground in order to explore the potential use of tiltmeters for monitoring the volume changes of glaciers.

\section{Mass-load Green's functions}

Green's functions are largely used to compute the deformation of the Earth due to surface loads (Longman, 1962, 1963; Farrell, 1972; Peltier, 1974). They are the response of the Earth to the gravitational and pressure forces exerted by a unit point mass at the surface. The deformation due to an extended surface load is then obtained by convolving the surface mass density describing the surface load with Green's functions. We use the formalism of Farrell (1972) to compute Green's functions of the displacement, gravity variation and tilt of the ground for both a homogeneous elastic half-space model and a realistic spherical, elastic, and gravitating Earth model.

The infinitesimal static displacement $\mathbf{u}$ of a self-gravitating continuum having a linear and isotropic elastic behaviour obeys the linearized equation of conservation of linear momentum where the derivative with respect to the time has been neglected

$$
\nabla \cdot \boldsymbol{\tau}+\rho_{0} \nabla\left(\mathbf{u} \cdot \mathbf{g}_{0}\right)-\rho_{0} \mathbf{g}_{0} \nabla \cdot \mathbf{u}+\rho_{0} \mathbf{g}_{1}=\mathbf{0}
$$

where $\rho_{0}$ is the density of the reference configuration, $\mathbf{g}_{0}$ is the unperturbed radial gravity, $\mathbf{g}_{1}$ is its Eulerian perturbation, and $\boldsymbol{\tau}$ is the elastic stress tensor:

$$
\boldsymbol{\tau}=\lambda \nabla \cdot \mathbf{u} \mathbf{I}+2 \mu \mathbf{e}
$$


I and e being the identity and infinitesimal deformation tensors, respectively, and $\lambda$ and $\mu$, the Lamé parameters.

In Eq. (1), the external body forces have been neglected. We also have the relation between gravity perturbation $\mathbf{g}_{1}$ and the Eulerian perturbation of the gravity potential, $\phi_{1}$ :

$$
\mathbf{g}_{1}=-\nabla \phi_{1}
$$

and Poisson's equation for $\phi_{1}$

$$
\nabla^{2} \phi_{1}=-4 \pi G \nabla \cdot\left(\rho_{0} \mathbf{u}\right)
$$

where $G$ is the Newtonian constant of gravitation.

As a boundary condition at the surface of the Earth model, we have that the normal traction is the normal force due to the weight of a unit point mass. The tangential tractions are assumed to be null.

\subsection{Half-space model}

Boussinesq's equation describes the deformation of a homogeneous elastic half-space. As presented in Farrell (1972) the initial gravity is not taken into account since it would be infinite for a mass distribution of infinite extent. He computed the displacement $\mathbf{u}$ by solving the purely elastic problem described by the following simplified equation for equilibrium:

$$
\eta \nabla \nabla \cdot \mathbf{u}+\mu \nabla^{2} \mathbf{u}=0
$$

where $\eta=\lambda+\mu$. The force exerted by the unit mass point is supposed to be $\mathbf{g}_{0}$, which is perpendicular to the surface of the half-space, its norm $g_{0}$ being taken as the unperturbed gravity at the surface of a realistic spherical Earth 
model. Next, the gravity variation is reintroduced in the problem through Poisson's equation (4) for the perturbation of gravity potential $\phi_{1}$, $\mathbf{u}$ being the solution of Eq. (5). By doing so, we compute the variation of gravity owing to the mass redistribution.

By using cylindrical coordinates $R, \varphi, z$ centered at the application point of the force, the solution of Eqs. (3), (4), and (5) at the surface $z=0$ of the half-space is given by

$$
\begin{gathered}
u_{R}(R, 0)=-\frac{g_{0}}{4 \pi R \eta}, \\
u_{z}(R, 0)=-\frac{g_{0}}{4 \pi \mu R} \frac{\sigma}{\eta}, \\
g_{1 R}(R, 0)=\frac{g_{0} \rho_{0} G}{2 \mu R}-\frac{G}{R^{2}},
\end{gathered}
$$

and

$$
g_{1 z}(R, 0)=\frac{g_{0} \rho_{0} G}{2 \mu R}
$$

where the $R$ - and $z$-components of the vectors are indicated by the subscripts $R$ and $z$, respectively. By symmetry, $u_{\varphi}=0, g_{1_{\varphi}}=0$, and neither $\mathbf{u}$ nor $\mathbf{g}_{1}$ depend on $\varphi$. The second term on the right-hand side of Eq. (8) stems from the direct gravitational attraction of the unit mass point. Because of the symmetry properties of the problem, there is no such term in the $z$-component of $\mathbf{g}_{1}(R, 0)$. Two other acceleration terms must be added to $\mathbf{g}_{1}$ to obtain the gravity variations that would be measured by a gravimeter at the surface of the Earth (Farrell, 1972; Dahlen et Tromp, 1998). Indeed, the gravimeter, attached to the surface of the Earth, is displaced in the initial gravity field of the spherical Earth model. Therefore, it experiences a variation of the vertical component of gravity that is the free-air gradient $2 g_{0} u_{z} / a$, where $a=6371 \mathrm{~km}$ is the mean radius of the Earth. Moreover, the tilt of the 
surface is responsible for a variation $g_{0} \partial u_{z} / \partial R$ of the $R$-component of the gravity field. Taking those two effects into account, Eqs (8) and (9) must be replaced by

$$
g_{1 R}^{a}=\frac{g_{0} \rho_{0} G}{2 \mu R}-\frac{G}{R^{2}}-g_{0} \frac{\partial u_{z}^{a}}{\partial R}
$$

and

$$
g_{1 z}^{a}=\frac{g_{0} \rho_{0} G}{2 \mu R}+\frac{2 g_{0}}{a} u_{z}^{a}
$$

respectively. From now on, the superscript $a$ indicates that the quantities are evaluated at the surface of the half-space. Tilt angle $t^{a}$ measured by a tiltmeter is the difference between the tilt of the ground and that of the geoid with respect to their initial horizontal position (Rerolle et al., 2006). We have

$$
\begin{aligned}
t^{a} & =\frac{\partial u_{z}^{a}}{\partial R}-\frac{g_{1}^{a}}{g_{0}} \\
& =-\frac{\rho_{0} G}{2 \mu R}+\frac{g_{0} \sigma}{4 \pi \mu \eta R^{2}}+\frac{G}{g_{0} R^{2}} .
\end{aligned}
$$

From Eqs (6), (7), and (11), we obtain the ratios

$$
\frac{g_{1 z}^{a}}{u_{z}^{a}}=-2 \pi G \rho_{0} \frac{\eta}{\sigma}+\frac{2 g_{0}}{a}
$$

and

$$
\frac{u_{R}^{a}}{u_{z}^{a}}=\frac{\mu}{\sigma}
$$

By taking $\lambda=3.29 \times 10^{10} \mathrm{~Pa}, \mu=2.56 \times 10^{10} \mathrm{~Pa}$, and $\rho_{0}=2500 \mathrm{~kg} / \mathrm{m}^{3}$, which correspond to a P-wave velocity of $5800 \mathrm{~m} / \mathrm{s}$ and a S-wave velocity of $3200 \mathrm{~m} / \mathrm{s}$, we have $g_{1}^{a} / u_{z}^{a}=0.235 \mu \mathrm{Gal} / \mathrm{mm}$, in agreement with the ratio found by de Linage et al. (2007) for a self-gravitating spherical elastic Earth model, and $u_{R}^{a} / u_{z}^{a}=0.304$. 


\subsection{Spherical Earth model}

We now consider a spherically symmetric, non-rotating, and elastically isotropic (SNREI) Earth model, a system of reference whose origin is at the center of the model, and spherical coordinates $r, \theta, \varphi$. Contrary to the half-space problem where we made ad hoc approximations to compute the gravity variations, there is now a direct coupling, described by Eqs (1)-(4), between the elastic deformation and gravity variations. Taking advantage of the spherical symmetry, we expand the displacement and stress fields in vector spherical harmonics, and the Eulerian pertubation of the gravity potential in spherical harmonics, to obtain an infinite set of decoupled spheroidal and toroidal systems of ordinary differential equations (Alterman et al., 1959). We numerically integrate the spheroidal system for the Preliminary Reference Earth Model (PREM) of Dziewonski and Anderson (1981) where we replace the ocean by a solid crust. In the following, we call this model the modified PREM. The density, seismic waves velocities and quality factors of the upper layer of the modified PREM are given in Table 1.

\section{Table 1}

At the surface, Green's functions for the vertical and horizontal displace- 
ments, are respectively given by:

$$
\begin{aligned}
& u_{z}^{s}(\psi)=\frac{G}{g_{0} a} \sum_{n=0}^{\infty} h_{n}^{\prime} P_{n}(\cos \psi), \\
& u_{t}^{s}(\psi)=\frac{G}{g_{0} a} \sum_{n=1}^{\infty} l_{n}^{\prime} \frac{\partial P_{n}(\cos \psi)}{\partial \psi} .
\end{aligned}
$$

where $P_{n}$ is the Legendre polynomial of degree $n, h_{n}^{\prime}$ and $l_{n}^{\prime}$ are the load Love numbers respectively for the vertical and the horizontal displacements, $\psi$ is the angular distance between the observation and loading points, and superscript $s$ indicates that Green's functions are evaluated at the surface.

The Lagrangian perturbation of the gravity is the sum of two terms. One is due to the elastic effect

$$
g^{s}(\psi)=\frac{G}{a^{2}} \sum_{n=0}^{\infty}\left[2 h_{n}^{\prime}-(n+1) k_{n}^{\prime}\right] P_{n}(\cos \psi),
$$

where $k_{n}^{\prime}$ is the load Love number for the Eulerian perturbation of the gravity potential. This part of the gravity change includes the correction $2 h_{n}^{\prime}$ for the free air gradient and the effect $-(n+1) k_{n}^{\prime}$ due to the mass redistribution.

The second term is due to the direct attraction of the loading point. If its altitude is $h_{\text {load }}$, the observation point being located at the altitude $h_{\text {obs }}$, the corresponding Green function for the variation of gravity is given by (Merriam, 1992; Boy et al., 2002):

$$
g_{N}^{s}(\psi)=G \frac{\left(a+h_{\mathrm{obs}}\right)-\left(a+h_{\mathrm{load}}\right) \cos \psi}{\left[\left(a+h_{\mathrm{obs}}\right)^{2}+\left(a+h_{\mathrm{load}}\right)^{2}-2\left(a+h_{\mathrm{obs}}\right)\left(a+h_{\mathrm{load}}\right) \cos (\psi)\right]^{3 / 2}} .
$$

Similarly ground tilt Green's function is also the sum of two terms,

$$
t^{s}(\psi)=-\frac{G}{g_{0} a^{2}} \sum_{n=1}^{\infty}\left(k_{n}^{\prime}-h_{n}^{\prime}\right) \frac{\partial P_{n}(\cos \psi)}{\partial \psi}
$$


due to the elastic deformation, and

$$
t_{N}^{s}(\psi)=\frac{G}{g_{0}} \frac{\left(a+h_{\text {load }}\right) \sin \psi}{\left[\left(a+h_{\mathrm{obs}}\right)^{2}+\left(a+h_{\mathrm{load}}\right)^{2}-2\left(a+h_{\mathrm{obs}}\right)\left(a+h_{\mathrm{load}}\right) \cos \psi\right]^{3 / 2}}
$$

for the tilt of the geoid due to the Newtonian attraction of the load.

$g_{N}^{s}$ and $t_{N}^{s}$, given by Eqs (18) and (20), are plotted in Fig. 1 for $h_{\mathrm{obs}}=0$ and 7 values of $h_{\text {load }}$.

\section{Figure 1}

To cut off the series in Eqs (15), (16), (17), and (19) at a finite integer $N$ and avoid Gibbs's phenomenon, we use Kummer's method (Farrell, 1972; Le-Meur and Hindmarsh, 2000; Barletta et al., 2006). We take $N=10000$ to guarantee a horizontal resolution of a few kilometers at the surface.

\subsection{Comparison between half-space and spherical models}

For small spatial scales, from some meters to several kilometers, the halfspace model is often adopted to estimate the Earth response to load variations (Bevis et al., 2004; Cavalié et al., 2007). For larger spatial scales, it is necessary to take the curvature of the Earth's surface into account as well as the rheology of the layers below the crust. To determine how well the deformation of a SNREI model can be approximated by that of a homogeneous half-space model, we compare Green's functions for the deformation of the two models. We consider a half-space with the same physical properties as 
the crust of the modified PREM (Table 1). In Figs 2 and 3, we plot various Green's functions and the absolute and relative differences $\Delta_{\text {abs }}$ and $\Delta_{\text {rel }}$ between Green's functions of the two models as a function of the distance between the observation and loading points. $\Delta_{\text {abs }}$ and $\Delta_{\text {rel }}$ are given by

$$
\begin{aligned}
& \Delta_{\text {abs }}(R, 0)=G^{a}-G^{s} \\
& \Delta_{\text {rel }}(R, 0)=\Delta_{\text {abs }} / G^{a}
\end{aligned}
$$

where $G^{a}$ and $G^{s}$ are Green's functions respectively given by Eqs (6)-(12) and Eqs (15)-(20). In Fig. 2 the amplitude of displacement and gravity Green's functions decreases by 6 orders of magnitude over $1000 \mathrm{~km}$, the amplitude of tilt Green's functions decreases by 12 orders of magnitude over the same distance. As shown by the $\Delta_{\text {abs }}$ 's and $\Delta_{\text {rel }}$ 's, Green's functions agree to within $1 \%$ up to $\sim 400 \mathrm{~m}$ from the load for the vertical displacement and elastic part of the gravity changes, $\sim 2 \mathrm{~km}$ for the horizontal displacement, and $\sim 5 \mathrm{~km}$ for the elastic part of the tilt. Further from the loading point, the relative differences increase. As shown in Fig. 3, the $10 \%$ relative difference happens at $\sim 2.5 \mathrm{~km}, \sim 6 \mathrm{~km}$, and $\sim 10 \mathrm{~km}$ from the load for the vertical displacement and elastic part of the gravity changes, the horizontal displacement and elastic part of the tilt variations, respectively.

\section{Figures 2 and 3}


Using Green's functions for the half-space and SNREI models, we investigate the ratios of tangential displacement to vertical displacement and elastic part of the gravity variations to vertical displacement. As noticed at the end of section 2.1 we find that the two ratios are constant for the half-space model. Indeed, as shown in Fig. 4, we have $u_{t}^{a} / u_{z}^{a}=0.304$ and $-g_{1 z}^{a} / u_{z}^{a}=-0.232 \mu \mathrm{Gal} / \mathrm{mm}$. The ratios $u_{t}^{s} / u_{z}^{s}$ and $g^{s} / u_{z}^{s}$ of the SNREI model are also represented in Fig. 4. The first ratio agrees to within $1 \%$ up to $\sim 400 \mathrm{~m}$ from the load and to within $10 \%$ between $\sim 400 \mathrm{~m}$ and $\sim 3 \mathrm{~km}$. The second ratio agrees to within $1 \%$ up to $\sim 4 \mathrm{~km}$ from the load and to within $15 \%$ between $\sim 4$ and $\sim 1000 \mathrm{~km}$.

\section{Figure 4}

For the computation of the loading effects, the extension of the load and the distance from the load do really matter. Llubes et al. (2004) showed that the hydrological contributions to gravity can be separated into three scales: a local scale up to $1-10 \mathrm{~km}$, a regional scale from $10 \mathrm{~km}$ up to 100 $\mathrm{km}$ and a global scale above $100 \mathrm{~km}$. We can clearly see from Figs. 2 and 3 that the deformation of the half-space is a very good approximation to the deformation of the SNREI model at the local scale. As Green's functions are rapidly varying functions near the load, especially for the tilt, it is difficult to interpolate them at the local scale. Then the deformation induced by 
the load variations at short distance from the load can be computed using the analytical Green's functions of the half-space model. This can apply, for example, to the zone near glaciers located in the same massif.

\subsection{Space convolution}

The displacement, gravity variation, and tilt of the ground due to ice thinning are obtained by convolving the ice-thickness variation $\Delta h$ with Green's functions $G_{n}$ given by Eqs (6)-(12) or (15)-(20):

$$
E(\theta, \varphi)=\rho_{\text {ice }} \iint_{\Omega} \Delta h\left(\theta^{\prime}, \varphi^{\prime}\right) G_{n}(\psi) d \Omega^{\prime},
$$

where $\Omega$ is the surface covered by the ice of density $\rho_{\text {ice }}$.

\section{Gravito-elastic deformation due to ice thinning in the Mont Blanc region (French Alps)}

In this section, we compute the gravito-elastic deformation induced by ice thinning of three glaciers in the Mont Blanc region. We have shown in the previous section that the deformation of a SNREI model at the local scale, up to $1-10 \mathrm{~km}$, can be approximated by the deformation of a homogeneous half-space model. We will show maps of gravity variation and deformation at places located further than $10 \mathrm{~km}$ from the glaciers. Therefore, it is necessary to base our calculation on a SNREI model.

\subsection{Ice-thickness data}

Ice-thickness variation $\Delta h$ from 1979 until 2003 has been deduced from the differential analysis of two DEMs (Berthier et al., 2004). The first model 
was built from aerial photographies taken in 1979, the second one, from images acquired by the SPOT 5 satellite in 2003. Detailed explanations can be found in Berthier et al. (2004). $\Delta h$ is shown in Fig. 5. The accuracy of these elevation changes has been assessed by comparison with precise $( \pm 30 \mathrm{~cm})$ transverse topographic profiles performed each year (Vincent et al., 2007). Differential DEM elevation changes have an accuracy of $2 \mathrm{~m}$. Although we do not take into account the time variability of the ice-thinning rate, we can mention that, for example, Berthier et al. (2004) give 3 rates for the glacier shrinkage at an elevation comprised between 1600 and $2100 \mathrm{~m}$ :

- 1979-1994: $1 \pm 0.4 \mathrm{~m} / \mathrm{yr}$,

- 1994-2000: $2.9 \pm 1.1 \mathrm{~m} / \mathrm{yr}$,

- 2000-2003: $4.1 \pm 1.7 \mathrm{~m} / \mathrm{yr}$.

Therefore, during the period 2000-2003, the ice-thinning rate is four times bigger than the 1979-1994 rate at low elevation. On the average over 24 years, it is approximately $2 \mathrm{~m} / \mathrm{yr}$.

In the next 3 subsections, we compute the effects of the ice thinning in the Mont Blanc area on a grid with a resolution of $20 \mathrm{~m}$. We only take into account 3 glaciers, which does not allow us to compare our results with Barletta et al.'s (2006) who consider the ice-mass loss all over the Alps. But we can study the gravito-elastic deformation due to the spatially nonhomogeneous ice thinning of a small group of glaciers with both a realistic geographical extension and realistic changes for the volume of the ice. Next, assuming that the ice-thinning rate has been constant since 1979, we obtain deformation rates. We take $\rho_{\text {ice }}=900 \mathrm{~kg} / \mathrm{m}^{3}$. 


\section{Figure 5}

\subsection{Displacement}

Fig. 6 shows the vertical displacement due to ice thinning for the modified PREM. The maximum displacement outside the glaciers is about $9 \mathrm{~mm}$ at $20 \mathrm{~m}$ from the glaciers for the 24 -year period (i.e. $0.38 \mathrm{~mm} / \mathrm{yr}$ ). It decreases with the distance from the thinning area. The horizontal displacement is shown in Fig. 7. It reaches up to $1.2 \mathrm{~mm}$ at $20 \mathrm{~m}$ on the West side of the icetongue of the Mer de Glace.

\section{Figures 6 and 7}

\subsection{Gravity changes}

Fig. 8 shows the elastic part of the gravity variation. It ranges from $-0.2 \mu \mathrm{Gal}$ to approximately $-2 \mu \mathrm{Gal}$ over the 24 -year period (i.e. from -0.008 to $-0.08 \mu \mathrm{Gal} / \mathrm{yr})$. The pattern is the same as that of the rebound but of opposite sign. The uplift and the associated free-air gradient variation effects (decreasing gravity) have a higher amplitude than the mass redistribution effects (increasing gravity). Since the altitude of the glaciers ranges from 1500 
$\mathrm{m}$ to $3500 \mathrm{~m}$, it is necessary to take into account the difference of altitude between the observation point and the thinning area. Fig. 9 shows the direct attraction due to the loss of ice computed with Eq. (18). If we add this to the gravity variation shown in Fig. 8, we obtain a total gravity variation of several hundreds $\mu \mathrm{Gal}$ over 24 years, which shows the strong influence of the topography on the gravity measurements in the close vicinity of the glaciers.

\section{Figures 8 and 9}

\subsection{Tilt of the ground}

The amplitude of the ground tilt due to 24 years of ice thinning reaches 15 $\mu \mathrm{rad}$ at $20 \mathrm{~m}$ from the glaciers, as shown in Fig. 10. The highest amplitude of the tilt outside the glaciers is near the ice tongue of the Mer de glace. There, the ice-thinning rate is the highest. The Newtonian part of the tilt is one order of magnitude smaller than the elastic part. The annual variation of the tilt reaches $0.63 \mu \mathrm{rad} / \mathrm{yr}$ at $20 \mathrm{~m}$ and $0.03 \mu \mathrm{rad} / \mathrm{yr}$ at $2 \mathrm{~km}$ from the glaciers. It rapidly decreases with the distance from the load variations.

Because of the unrealistic assumption of a constant ice-thinning rate, the displacement, gravity and ground-tilt rates are probably underestimated for the 1994-2003 period and overestimated for the 1979-1994 period, at least if the ice-thinning rate increased with time everywhere as it did at low elevation 
(Berthier et al., 2004).

\section{Figure 10}

\section{Induced deformation at $\mathrm{Ny}$-Ålesund in Svalbard, Norway}

To compute the effects of the present-day ice thinning at Ny-Ålesund in Svalbard, Norway, we use the modified PREM model and the SVAL model of Hagedoorn and Wolf (2003) in which the 16 major ice masses, each one made up of several glaciers, are approximated by co-axial elliptical cylinders. The model gives an extension of the ice-covered area as well as an approximate topography of ice masses. We assume a constant thinning rate averaged over Svalbard of $47 \mathrm{~cm} / \mathrm{yr}$ and a density of $1000 \mathrm{~kg} / \mathrm{m}^{3}$ as used by Sato et al. (2006). Our grid has a resolution of 0.001 degree in both longitude and latitude. The coordinates of the Global Geodynamics Project (GGP) station at $\mathrm{Ny}$-Ålesund are $78.931^{\circ} \mathrm{N}, 11.867^{\circ} \mathrm{E}$ and its altitude is $43 \mathrm{~m}$. The 3 nearest ice masses are from $\sim 9$ up to $\sim 80 \mathrm{~km}$ away from the station. The 13 others ice masses are further than $\sim 100 \mathrm{~km}$ from the station. We compute the effects for the whole set of ice masses as well as the total contribution of the ice masses at the GGP station. The results are given in Table 2. We see that the uplift induced by the thinning of the 16 ice masses is $2.04 \mathrm{~mm} / \mathrm{yr}$, $62.26 \%$ of this rate being due to the 3 nearest ice masses. The gravity 
rates have been deduced from two computations. The first one includes neither the topography of the ice masses nor the altitude of the station. We obtain a total gravity variation rate of $-0.52 \mu \mathrm{Gal} / \mathrm{yr}$. The 3 nearest ice masses are responsible for $61.54 \%$ of this rate. The second computation includes the effect of the topography of the ice masses and the altitude of the station. The gravity rate due to the 16 ice masses is $-0.48 \mu \mathrm{Gal} / \mathrm{yr}$, which is smaller in absolute value than in the first case because the effects of the thinning areas which are above and below the horizontal plane at the station, especially for the surrounding ice masses, act in opposite senses. The surrounding ice masses are responsible for $58.33 \%$ of this rate; the contribution from the other ice masses, which is $-0.20 \mu \mathrm{Gal} / \mathrm{yr}$, is the same as in the first computation where we did not take the topography of the ice masses into account. The magnitude of the tilt rates are 70.26 and 37.97 $\mathrm{nrad} / \mathrm{yr}$ respectively for the West-East (positive in the East direction) and South-North (positive in the North direction) components. The thinning of the 3 nearest ice masses contibute for $90 \%$ to the tilt of the ground.

Sato et al. (2006) suggested an ice-thinning rate of $\sim 70-80 \mathrm{~cm} / \mathrm{yr}$ to explain the present-day ice-thinning contribution to the rebound observed by VLBI and GPS. But this rate fails to explain the absolute gravity variations associated to the elastic deformation due to present-day ice-thinning. Kohler et al. (2007) estimated the ice-thinning rate from DEMs for the Midtre Lovénbreen glacier located within $5 \mathrm{~km}$ from Ny-Ålesund. For the period 2003-2005, they obtain a rate of $\sim 69 \mathrm{~cm} / \mathrm{yr}$, which is almost 1.5 times bigger than the mean rate we used to estimate the effects induced by ice thinning. This rate is in agreement with that proposed by Sato et al. (2006). 
The Midtre Lovénbreen glacier is half-way between the station and the nearest ice mass in the SVAL model. Such a rate close to the station suggests that the tilt rates we have obtained from the SVAL model are underestimated. A better estimation of the thinning rates could be computed in the future by considering DEMs from the SPIRIT project (Korona et al., 2009) or ICESAT altimetric profiles (Kääb, 2008).

\section{Observations of deformation and gravity variation}

The ground displacement near ice masses can be monitored by using GPS and VLBI measurements. Sjöberg et al. (2004) analyzed three epochs of GPS campaigns over a period of 7 years, from 1992 to 1999. They obtained uplift rates comprised between 5 and $19 \mathrm{~mm} / \mathrm{yr}$ near the Vatnajökull ice cap in Iceland. Sato et al. (2006) derived ground-displacement rates from GPS and VLBI measurements at Ny-Ålesund. They found a rebound of $\sim 5 \mathrm{~mm} / \mathrm{yr}$ for the periods 1998-2004 and 1994-2004 respectively associated to the GPS and VLBI measurements. Khan et al. (2007) observed an elastic uplift of $\sim 35 \mathrm{~mm}(\sim 7 \mathrm{~mm} / \mathrm{yr})$ at the GPS site in Kulusuk, Greenland, due to the rapid thinning of ice between 2001 and 2006 in the southeastern sector of the Greenland ice sheet. These strong uplifts occured in regions where large ice masses experienced high thinning rates. As shown in Section 3.2 the rebound due to 24 years of ice thinning in the Alps over a small area is smaller, at most $9 \mathrm{~mm}(0.38 \mathrm{~mm} / \mathrm{yr})$, and identifying such a small contribution to the total uplift in the GPS measurements remains a difficult task.

Sato et al. (2006) also derived gravity variations at Ny-Ålesund from repeated absolute gravity measurements and found a rate of $-2.5 \mu \mathrm{Gal} / \mathrm{yr}$ 
for the period 1998-2003. This rate includes different effects such as the postglacial rebound and the present-day ice thinning. The small gravity variation signal expected from the latter, about $-0.5 \mu \mathrm{Gal} / \mathrm{yr}$ (Table 2), suggests that it is difficult to observe far from the thinning area by using gravimeters. The gravity variation close to the glaciers, which is much bigger (Section 3.3), would give a larger signal that would be easy to observe provided a gravimeter can be installed near the glaciers.

The sensitivity of the tiltmeters depends on the variability of the environment parameters, for instance the temperature, and type of instrument. Indeed, to decrease the influence of the temperature variation, the tiltmeters are often installed in mine galleries. Besides, the long-baseline hydrostatic tiltmeters are less sensitive to the local heterogeneities than the short-baseline tiltmeters and are also more stable (Boudin, 2004; d'Oreye et al., 2005; Boudin et al., 2008). The accuracy of a 100 meter-long tiltmeter is $1 \times 10^{-4} \mu \mathrm{rad}$ and its time stability is better than $1 \times 10^{-1} \mu \mathrm{rad} / \mathrm{yr}$ (Rerolle et al., 2006). d'Oreye et al. (2005) developed and installed their instrument in an underground mine where they obtained a drift rate that did not exceed $5 \times 10^{-3} \mu \mathrm{rad} / \mathrm{month}$ and a sensitivity of $5 \times 10^{-6} \mu \mathrm{rad}$ in the long-period seismic band and $34 \times 10^{-6} \mu \mathrm{rad}$ for longer periods. Recently, Boudin et al. (2008) have shown that the stabilities of two 100 meter-long tiltmeters installed in a mine in the Vosges massif in France are $6.5 \times 10^{-3} \mu \mathrm{rad} / \mathrm{month}$ and $10 \times 10^{-3} \mu \mathrm{rad} / \mathrm{month}$ and a low noise level of the order of $1 \times 10^{-5} \mu \mathrm{rad}$. They also indicate that such instruments in similar conditions are suitable for the monitoring of long-term tilt rates lower than $1 \times 10^{-1} \mu \mathrm{rad} / \mathrm{yr}$. Our computation of ground tilt because of shrinking ice masses in the Alps and 
Svalbard shows that the expected signal is well above the instrumental noise and that it should be measurable even if the instrument is not installed in the close vicinity of the glaciers. If the conditions for installing high-precision tiltmeters are fulfilled, then hydrostatic tiltmeter measurements are potentially appropriate to monitor the ice thinning of nearby glaciers.

\section{Conclusion}

We have computed Green's functions of the vertical and horizontal displacements, gravity change and ground tilt for a homogeneous half-space model and a realistic spherical Earth model. We have compared Green's functions for the two models and confirmed that the half-space approximation is sufficient to model the Earth deformation at the local scale (1 to 10 $\mathrm{km}$ away from the load) .

We have also given the amplitude and geographical extension of the displacements, gravity variations and ground tilt changes induced by the thinning of 3 glaciers in the Mont Blanc region, where ice-thickness variations were previously measured over a 24-years period, and by a homogeneous thinning of the glaciers of Svalbard. We have shown that taking into account the topography of both the surrounding ice-free regions and glaciers is necessary to estimate the magnitude of the gravity variations. We have deduced the tilt rates due to the load variations and compared them with the sensitivity and time stability of available long-baseline tiltmeters. For the 3 glaciers of the Mont Blanc massif that we have considered and the glaciers of Svalbard, it should be possible to monitor the local ice-mass variations with hydrostatic tiltmeters, if they were installed at appropriate sites. The 
seasonal and annual signals could then be extracted. Finally, for the sites where continuous GPS and gravity measurements are already made, such as in the Ny-Ålesund GGP station, tilt measurements would provide a useful complementary information. Moreover, local ground data, often sparse in time and space, would benefit from the integrated view and continuous recording of tiltmeters.

\section{Acknowledgements}

A. Memin acknowledges financial support from the Centre National d'Etudes Spatiales. We thank T. Sato for providing the SVAL model and two anonymous reviewers for their suggestions and constructive comments.

\section{References}

Alterman Z., Jarosch H. \& Pekeris L., 1959. Oscillations of the Earth, Proc. Roy. Soc. Lond., Ser. A, 252, 80-95.

Arendt A. A., Echelmeyer K. A., Harrison W. D., Lingle C. S., \& Valentine V. B., 2002. Rapid wastage of Alaska glaciers and their contribution to rising sea level, Science, 297, 5580, 382-386.

Barletta V. R., Ferrari C., Diolaiuti G., Carnielli T., Sabadini R., and Smiraglia C., 2006. Glacier shrinkage and modeled uplift of the Alps, Geophys. Res. Lett., 33, L14307, doi:10.1029/2006GL026490.

Barletta V. R., Sabadini R., and Bordoni A., 2008. Isolating the PGR signal in the GRACE data: impact on mass balance estimates in Antarctica and Greenland, Geophys. J. Int., 172, 18-30. 
Berthier E., Arnaud Y., Baratoux D., Vincent C., \& Rémy F., 2004. Recent rapid thinning of the 'Mer de Glace' glacier derived from satellite optical images, Geophys. Res. Lett., 31, 17, L17401, doi:10.1029/2004GL020706.

Berthier E., Arnaud Y., Kumar R., Ahmad S., Wagnon P., \& Chevallier P., 2007. Remote sensing estimates of glacier mass balances in the Himachal Pradesh (Western Himalaya, India), Remote Sensing Environ., 108, 3, $327-338$.

Bevis M., Kendrick E., Cser A., \& Smalley R.Jr., 2004. Geodetic measurement of the local elastic response to the changing mass of water in Lago Laja, Chile, Phys. Earth Planet. Inter., 141, 71-78.

Boudin F., 2004. Développement et validation d'un inclinomètre longue base de subsurface à silice et mercure: Application à des mesures géophysiques de haute résolution sur le chantier pilote du Golfe de Corinthe, Ph.D. Thesis, Université Paris 7, 300 pp.

Boudin F., Bernard P., Longuevergne L., Florsch N., Larmat C., Courteille C., Blum P.-A., Vincent T., \& Kammentaler M., 2008. A silica long base tiltmeter with high stability and resolution, Rev. Scient. Inst., 79, doi:10.1063/1.2829989.

Boy J.-P., Gegout P. and Hinderer J., 2002. Reduction of surface gravity data from global atmospheric pressure loading., Geophys. J. Int., 149, 534-545.

Cavalié O., Doin M.-P., Lasserre C., \& Briole P., 2007. Ground motion measurement in the Lake Mead area, Nevada, by differential synthetic aperture 
radar interferometry time series analysis: Probing the lithosphere rheological structure, J. Geophys. Res., 112, B03403, doi:10.1029/2006JB004344.

Cazenave A., 2006. How fast are the ice sheets melting?, Science, 10.1126/science.1133325.

Chen J. L., Tapley B. D., \& Wilson C. R., 2006. Alaskan mountain glacial melting observed by satellite gravimetry, Earth Planet. Sci. Lett., 248, 368-378.

Chen J. L., Wilson C. R., Tapley B. D., Blankenship D. D., \& Ivins E. R., 2007. Patagonia Icefield melting observed by Gravity Recovery and Climate Experiment (GRACE), Geophys. Res. Lett., 34, L22501, doi:10.1029/2007GL031871.

Dahlen F. A. and Tromp J., 1998. Theoretical Global Seismology, Princeton University Press, Princeton, New Jersey, 1205 pp.

Dziewonski A. M. \& Anderson D. L., 1981. Preliminary reference Earth model, Phys. Earth Planet. Inter., 25, 297-356.

Farrell W. E., 1972. Deformation of the Earth by surface loads, Rev. Geophys. Space Phys., 10, 761-797.

Hagedoorn J. M. \& Wolf D., 2003, Pleistocene and Recent deglaciation in Svalbard: implications for tide-gauche, GPS and VLBI measurements, $J$. Geodyn., 35, 415-423, doi: 10.1016/S0264-3707(03)00004-8.

Horwath M. and Dietrich R., 2009. Signal and error in mass change inferences from GRACE: the case of Antarctica, Geophys. J. Int., 177, 849-864. 
Howat I. M., Joughin I., \& Scambos T. A., 2007. Rapid Changes in Ice Discharge from Greenland Outlet Glaciers.Science,315,5818, 1559-1561.

Kääb A., 2008. Glacier volume changes using ASTER satellite stereo and ICESat GLAS laser altimetry. A test study on Edgeøya, Eastern Svalbard, IEEE Transactions on Geoscience and Remote Sensing, 46, 10, 2823-2830.

Khan S. A., Wahr J., Stearns L. A., Hamilton G. S., van Dam T., Larson K. M., \& Francis O., 2007. Elastic uplift in southeast Greenland due to rapid ice mass loss, Geophys. Res. Lett., 34, L21701, doi:10.1029/2007GL31468.

Kohler J., James T. D., Murray T., Nuth C., Brandt O., Barrand N. E., Aas H. F., \& Luckman A., 2007. Acceleration in thinning rate on western Svalbard glaciers, Geophys. Res. Lett., 34, L18502, doi:10.1029/2007GL030681.

Korona J., Berthier E., Bernard M., Remy F., \& Thouvenot E., 2009. SPIRIT. SPOT 5 stereoscopic survey of Polar Ice: Reference Images and Topographies during the fourth International Polar Year (2007-2009), ISPRS Journal of Photogrammetry and Remote Sensing, 64, 204-212.

Le Meur E. \& Hindmarsh R. C. A., 2000. A comparison of two spectral approaches for computing the Earth response to surface loads, Geophys. J. Int., 141, 282-298.

de Linage C., Hinderer J., \& Rogister Y., 2007. A search for the ratio between gravity variation and vertical displacement due to a surface load, Geophys. J. Int., 171, 986-994, doi:10.1111/j.1365-246X.2007.03613.x.

Llubes M., Florsch N., Hinderer J., Longuevergne L., \& Amalvict M., 2004, Local hydrology, the Global Geodynamics Project and 
CHAMP/GRACE perspective: some case studies, J. Geodyn., 28, 355374, doi: 10.1016/j.jog.2004.07.015.

Llubes M., Florsch N., Boy J.-P., Amalvict M., Bonnefond P., Bouin M.N., Durand S., Esnoult M.-F., Exertier P., Hinderer J., Lalancette M.-F., Masson F., Morel L., Nicolas J., Vergnolle M., and Wöppelmann G., 2008, Multi-technique monitoring of ocean tide loading in Northern France, C.R. Geoscience, 340, Iss. 6, 379-389, doi: 10.1016/j.crte.2008.03.005.

Longman I. M., 1962. A Green's function for determining the deformation of the Earth under surface mass loads. 1. Theory, J. Geophys. Res., 67, 845-850.

Longman I. M., 1963. A Green's function for determining the deformation of the Earth under surface mass loads. 2. Computations and numerical results, J. Geophys. Res., 68, 485-496.

Magnùsson E., Björnsson H., Dall J., \& Palsson F., 2005. Volume changes of Vatnajokull ice cap, Iceland, due to surface mass balance, ice flow, and subglacial melting at geothermal areas, Geophys. Res. Lett., 32, 5.

Meier M. F., Dyurgerov M. B., Rick U. K., O’Neel S., Pfeffer W. T., Anderson R. S., Anderson S. P., \& Glazovsky A. F., 2007. Glaciers dominate Eustatic sea-level rise in the 21st century, Science , 317, 5841, 1064-1067.

Merriam J. B., 1992. Atmospheric pressure and gravity, Geophys. J. Int.,109, $488-500$. 
d'Oreye N. F. \& Zürn W., 2005. Very high resolution long-baseline watertube tiltmeter to record small signals from Earth free oscillations up to secular tilts, Rev. Sci. Instrum., 76, 2, 024501, doi:10.1063/1.1844451.

Pagli C., Sigmundsson F., Lund B., Sturkell E., Geirsson H., Einarsson P., Arnadottir T., \& Hreinsdottir S., 2007. Glacio-isostatic deformation around the Vatnajokull ice cap, Iceland, induced by recent climate warming: GPS observations and finite element modeling, J. Geophys. Res., 112, B8.

Peltier W. R., 1974. The Impulse Response of a Maxwell Earth. Rev. Geophys. Space Phys., 12, 4, 649-669.

Rabatel A., Francou B., Jomelli V., Naveau P., \& Grancher D., 2008. A chronology of the Little Ice Age in the tropical Andes of Bolivia $\left(16^{\circ} \mathrm{S}\right)$ and its implications for climate reconstruction, Quaternary Research, 70, 198-212.

Rerolle T., Florsh N., Llubes M., Boudin F., \& Longuevergne L., 2006. L'inclinométrie, un nouvel outil pour le suivi temporel des aquifères ?, C. R. Geoscience, 338, 775-786.

Rignot E., Rivera A., \& Casassa, G., 2003. Contribution of the Patagonia Icefields of South America to sea level rise, Science, 302, 5644, 434-437.

Rignot E., Bamber J. L., Van den Broecke M. R., Davis C., Li Y., Van de Berg W. J., \& Van Meijgaard E., 2008. Recent Antarctic ice mass loss from radar interferometry and regional climate modelling, Nature, 1, 106-110. 
Sato T., Okuno J., Hinderer J., MacMillan D. S., Plag H. P., Francis O., Falk R., \& Fukuda Y., 2006. A geophysical interpretation of the secular displacement and gravity rates observed at $\mathrm{Ny}$-Ålesund, Svalbard in the Arctic-effects of post-glacial rebound and present-day ice melting, Geophys. J. Int., 165, 729-743.

Sjöberg L. E., Pan M., Erlingsson S., Asenjo E., \& Arnason K., 2004. Land uplift near Vatnajökull, Iceland, as observed by GPS in 1992, 1996 and 1999, Geophys. J. Int., 159, 943-948.

Slobbe D. C., Ditmar P. and Lindenbergh R. C., 2009. Estimating the rates of mass change, ice volume change and snow volume change in Greenland from ICESat and GRACE data, Geophys. J. Int., 176, 95-106.

Stearns L. A. \& Hamilton G. S., 2007. Rapid volume loss from two East Greenland outlet glaciers quantified using repeat stereo satellite imagery, Geophys. Res. Lett., 34, L05503, doi:10.1029/2006GL028982.

Vincent C., Le Meur E., Six D. \& Funk M., 2005. Solving the paradox of the end of the Little Ice Age in the Alps, Geophys. Res. Lett., 32, L09706, doi:10.1029/2005GL022552.

Vincent C., Le Meur E., Six D., \& Thibert E., 2007. Un service d'observation des glaciers des Alpes françaises "glacioclim-alpes", pour quoi faire ? La Houille Blanche, 03, 86-95.

Watson G. N., 1966. A treatise on the Theory of Bessel Functions, Cambridge University Press, New York, 804 pp. 
Table 1 Density, seismic wave velocities $V_{p}$ and $V_{s}$ and quality factors $Q_{\mu}$ and $Q_{\kappa}$ of the crust that replaces the ocean layer in the PREM model of Dziewonski and Anderson (1981).

Table 2 Deformation induced at the Ny-Ålesund GGP station in Svalbard, Norway, by the SVAL model with an ice-thinning rate of $47 \mathrm{~cm} / \mathrm{yr}$ and density of $1000 \mathrm{~kg} / \mathrm{m}^{3}$. Numbers in bold are for the gravity and tilt rates that take into account the topography of the ice masses.

Figure 1 Green functions for the gravity variation $g_{N}^{s}$ and tilt $t_{N}^{s}$ of a spherical Earth model due to the gravitational attraction of the load, given

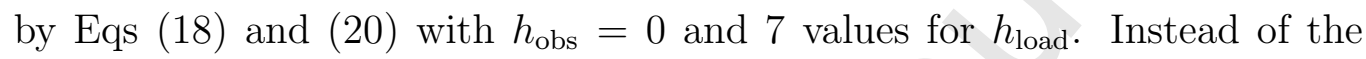
angular distance $\psi$, the abscissa is the distance $a \psi$.

Figure 2 Green's functions for a homogeneous half-space model (solid lines) and a spherical model (dashed lines). Black, cyan, red and green curves refer respectively to the vertical and horizontal displacements and non-Newtonian gravity and tilt changes. The dotted dashed lines represent the absolute differences $\Delta_{\text {abs }}$ (Eq. 21).

Figure 3. Relative differences $\Delta_{\text {rel }}$ (Eq. 22) between Green's functions of half-space and spherical models with respect to the half-space model. Black, cyan, red and green curves refer respectively to the vertical and horizontal displacements and non-Newtonian gravity and tilt changes.

Figure 4. Ratios of Green's functions: $u_{t}^{a} / u_{z}^{a}$ (dashed red line), $u_{t}^{s} / u_{z}^{s}$ (solid red line), $-g_{1 z}^{a} / u_{z}^{a}$ (dashed black line), and $g^{s} / u_{z}^{s}$ (solid black line) as a function of the distance to the loading point. The last two ratios are in $\mu \mathrm{Gal} / \mathrm{mm}$ whereas the two first are dimensionless. 
Figure 5. Ice-thickness variation (in m) between 1979 and 2003 in the Mont Blanc region that includes the three glaciers of the Mer de Glace, Talèfre and Leschaux (Berthier et al., 2004). The highest and lowest altitudes are also indicated.

Figure 6. Vertical displacement (in $\mathrm{mm}$ ) due to the ice thinning in the Mont Blanc area for the modified PREM. Glaciers are filled in black.

Figure 7. Horizontal displacement (in $\mathrm{mm}$ ) due to the ice thinning in the Mont Blanc area for the modified PREM. The arrows indicate the direction of the motion of the ground and the colored background shows the amplitude of the displacement. Glaciers are filled in black.

Figure 8. Elastic part of the gravity effects (in $\mu \mathrm{Gal}$ ) due to the icethinning in the Mont Blanc area for the modified PREM. Glaciers are filled in black.

Figure 9. Newtonian part of the gravity effects (in $\mu \mathrm{Gal}$ ) due to the ice thinning in the Mont Blanc area for the modified PREM. Glaciers and the region with no topography data are filled in black. Note that the color scale is opposed to that in the former figures.

Figure 10. Tilt changes (in $\mu \mathrm{rad}$ ) due to the ice thinning in the Mont Blanc area for the modified PREM. The arrows indicate the direction of the tilt of the ground and the colored background shows the amplitude of the tilt variations. To have a clear picture of the area where the tilt is significant, we show the tilt changes up to $3 \mu \mathrm{rad}$ only. Glaciers are filled in black. 
Table 1: Density, seismic wave velocities $V_{p}$ and $V_{s}$ and quality factors $Q_{\mu}$ and $Q_{\kappa}$ of the crust that replaces the ocean layer in the PREM model of Dziewonski and Anderson (1981).

\begin{tabular}{ccccc}
\hline Density $\left(\mathrm{kg} / \mathrm{m}^{3}\right)$ & $V_{p}(\mathrm{~m} / \mathrm{s})$ & $V_{s}(\mathrm{~m} / \mathrm{s})$ & $Q_{\mu}$ & $Q_{\kappa}$ \\
\hline 2600 & 5800 & 3200 & 600 & 57823 \\
\hline
\end{tabular}


Table 2: Deformation induced at the Ny-Ålesund GGP station in Svalbard, Norway, by the SVAL model with an ice thinning rate of $47 \mathrm{~cm} / \mathrm{yr}$ and density of $1000 \mathrm{~kg} / \mathrm{m}^{3}$. Numbers in bold are for the gravity and tilt rates that take into account the topography of the ice-masses

\begin{tabular}{|c|c|c|c|c|}
\hline & $\begin{array}{c}16 \\
\text { ice-masses }\end{array}$ & $\begin{array}{c}3 \\
\text { ice-masses }\end{array}$ & $\frac{13}{\text { ice-masses }}$ & $\begin{array}{c}16 \text { ice-masses } \\
\text { Sato et al. (2006) }\end{array}$ \\
\hline $\begin{array}{c}\text { Vertical } \\
\text { displacement } \\
(\mathrm{mm} / \mathrm{yr})\end{array}$ & 2.04 & $1.27(62.26 \%)$ & $0.77(37.74 \%)$ & 2.04 \\
\hline $\begin{array}{c}\text { Gravity } \\
(\mu \mathrm{Gal} / \mathrm{yr}) \\
\end{array}$ & $\begin{array}{r}-0.52 \\
-0.48\end{array}$ & $\begin{array}{r}-0.32(61.54 \%) \\
\mathbf{- 0 . 2 8}(\mathbf{5 8 . 3 3} \%) \\
\end{array}$ & $\begin{array}{r}-0.20(38.46 \%) \\
\mathbf{- 0 . 2 0}(\mathbf{4 1 . 6 7 \% )} \\
\end{array}$ & $\begin{array}{c}-0.53 \\
-\end{array}$ \\
\hline $\begin{array}{c}\text { Tilts (nrad/yr) } \\
\text { West-East } \\
\text { South-North }\end{array}$ & $\begin{array}{l}-70.26 \\
37.97\end{array}$ & $\begin{array}{l}-32.14(88.44 \%) \\
37.90(99.82 \%)\end{array}$ & $\begin{array}{c}-8.12(11.56 \%) \\
0.07(0.18 \%)\end{array}$ & - \\
\hline
\end{tabular}



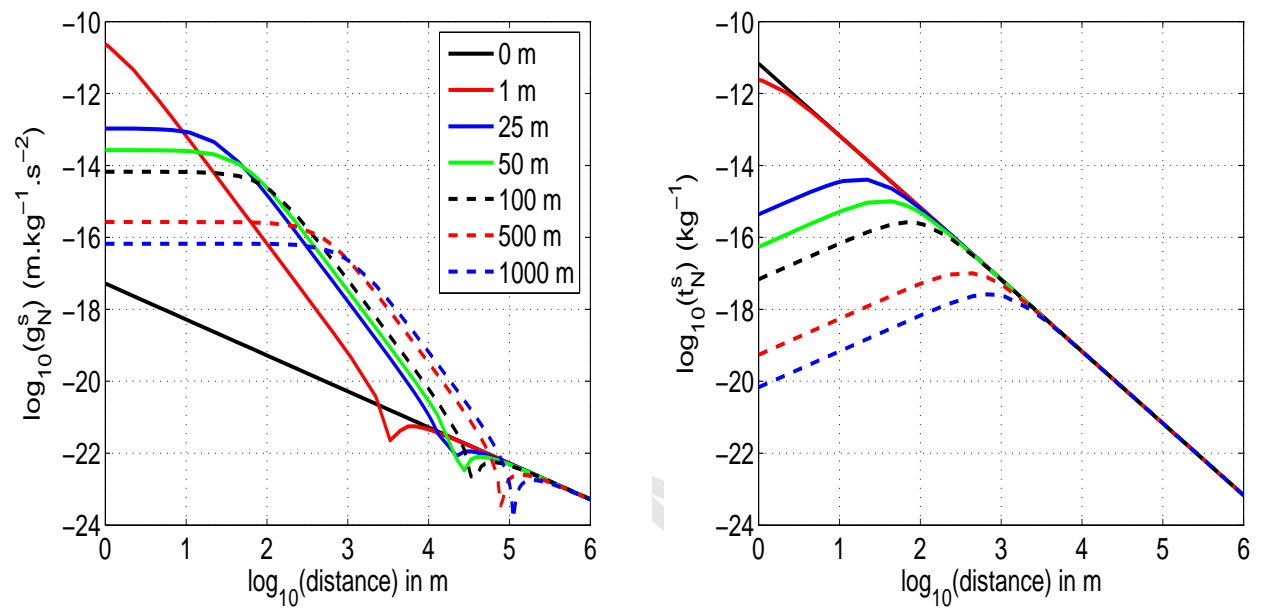

Figure 1: Green functions for the gravity variation $g_{N}^{s}$ and tilt $t_{N}^{s}$ of a spherical Earth model due to the gravitational attraction of the load, given by Eqs (18) and (20) with $h_{\text {obs }}=0$ and 7 values for $h_{\text {load }}$. Instead of the angular distance $\psi$, the abscissa is the distance $a \psi$. 

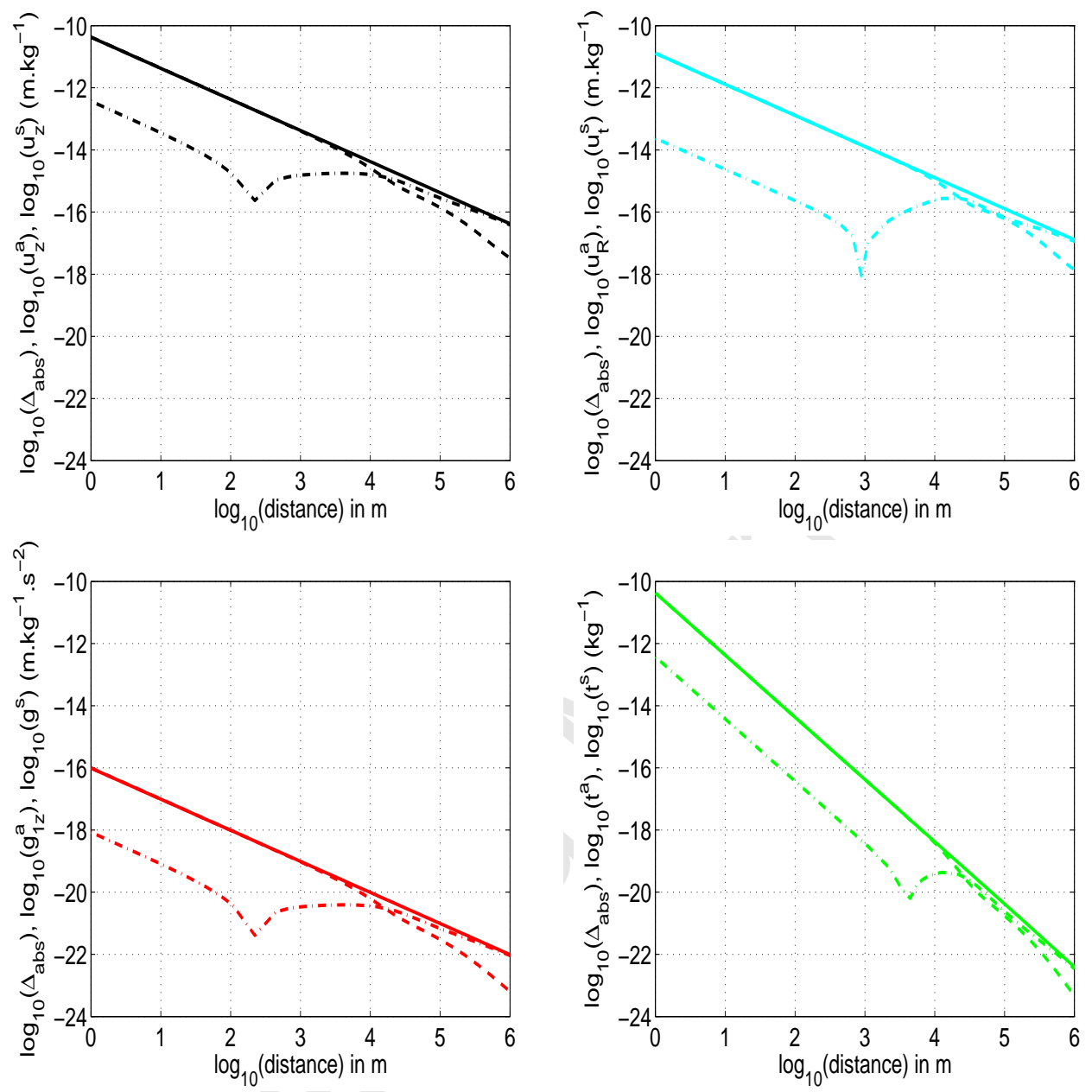

Figure 2: Green's functions for a homogeneous half-space model (solid lines) and a spherical model (dashed lines). Black, cyan, red and green curves refer respectively to the vertical and horizontal displacements and non-Newtonian gravity and tilt changes. The dotted dashed lines represent the absolute differences $\Delta_{\text {abs }}$ (Eq. 21). 


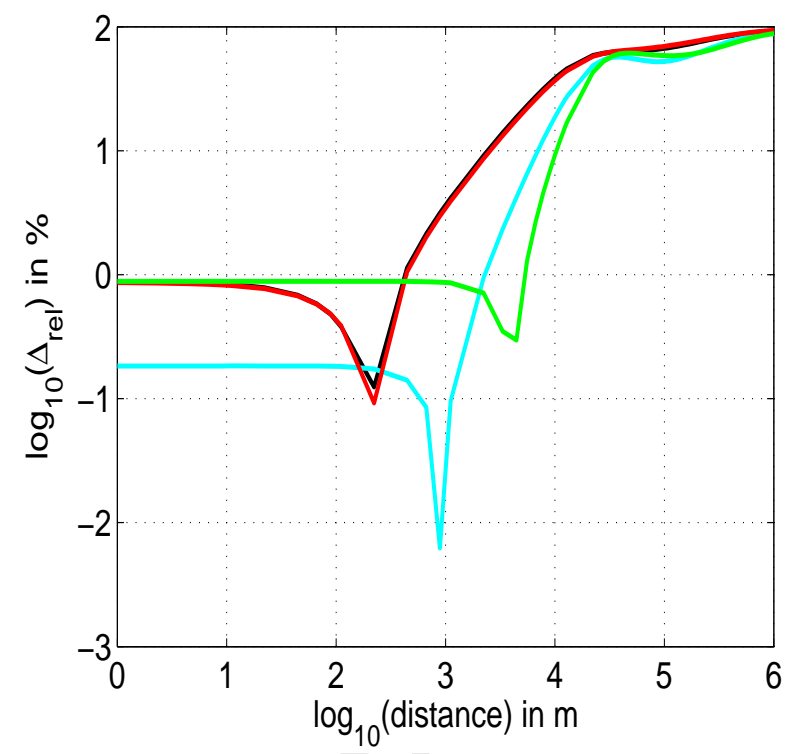

Figure 3: Relative differences $\Delta_{\text {rel }}$ (Eq. 22) between Green's functions of half-space and spherical models with respect to the half-space model. Black, cyan, red and green curves refer respectively to the vertical and horizontal displacements and non-Newtonian gravity and tilt changes. 


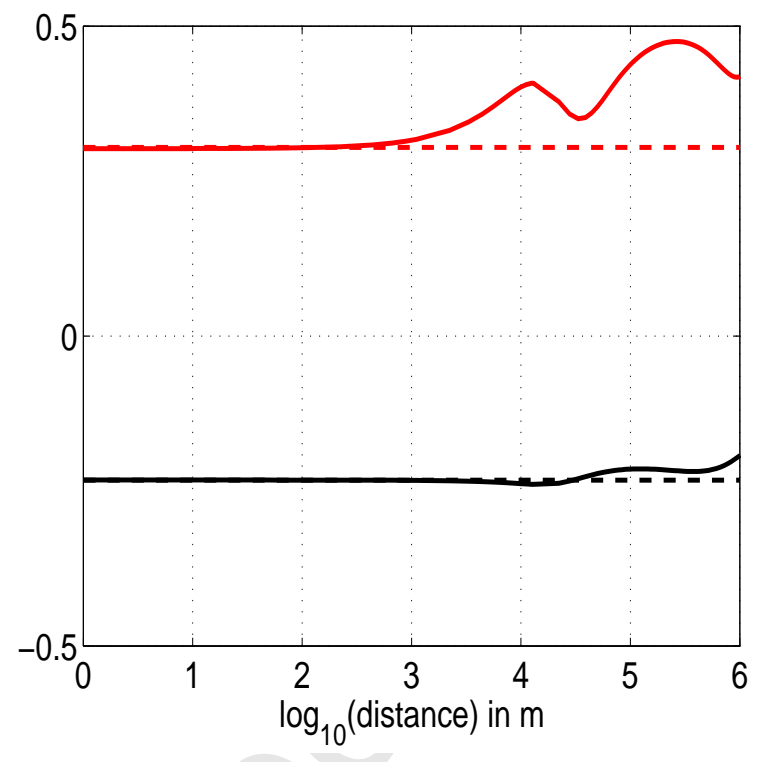

Figure 4: Ratios of Green's functions: $u_{t}^{a} / u_{z}^{a}$ (dashed red line), $u_{t}^{s} / u_{z}^{s}$ (solid red line), $-g_{1 z}^{a} / u_{z}^{a}$ (dashed black line), and $g^{s} / u_{z}^{s}$ (solid black line) as a function of the distance to the loading point. The last two ratios are in $\mu \mathrm{Gal} / \mathrm{mm}$ whereas the two first are dimensionless. 


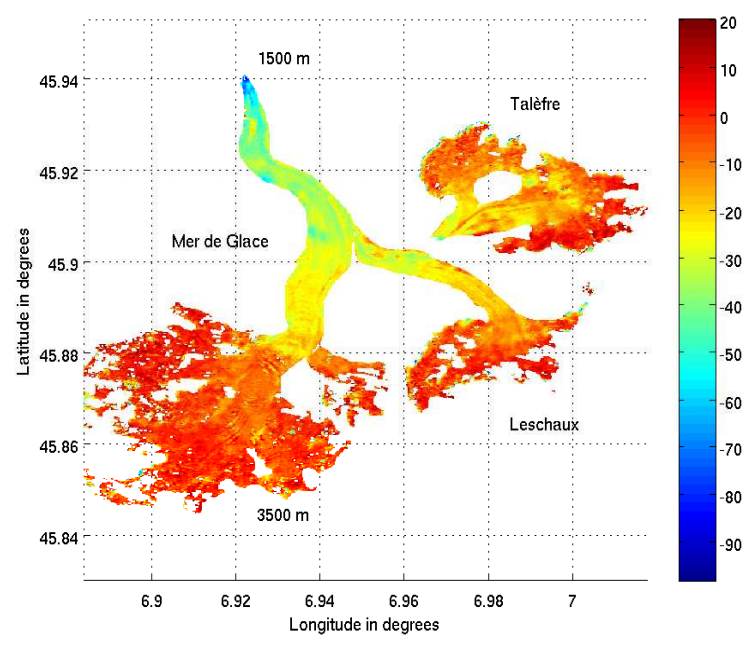

Figure 5: Ice-thickness variation (in m) between 1979 and 2003 in the Mont Blanc region that includes the three glaciers of the Mer de Glace, Talèfre and Leschaux (Berthier et al., 2004). The highest and lowest altitudes are also indicated. 


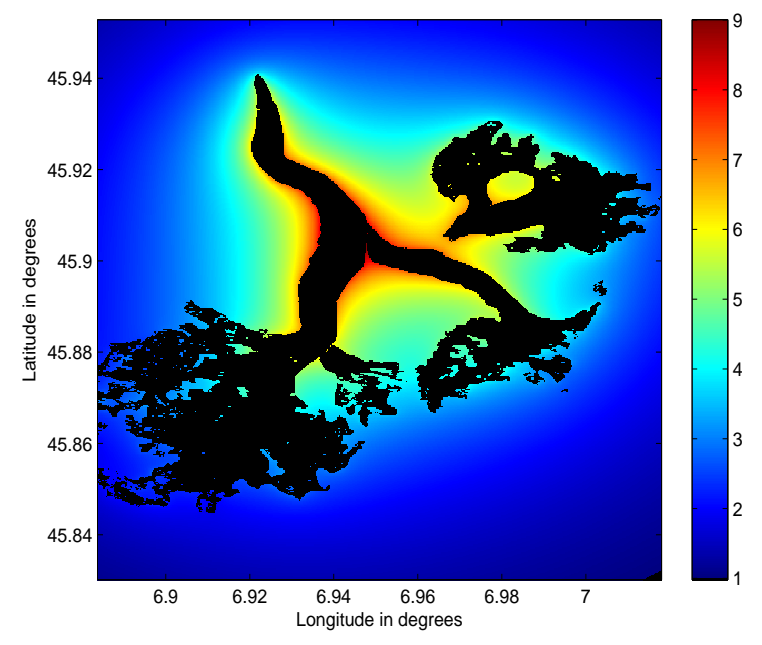

Figure 6: Vertical displacement (in $\mathrm{mm}$ ) due to the ice thinning in the Mont Blanc area for the modified PREM. Glaciers are filled in black. 


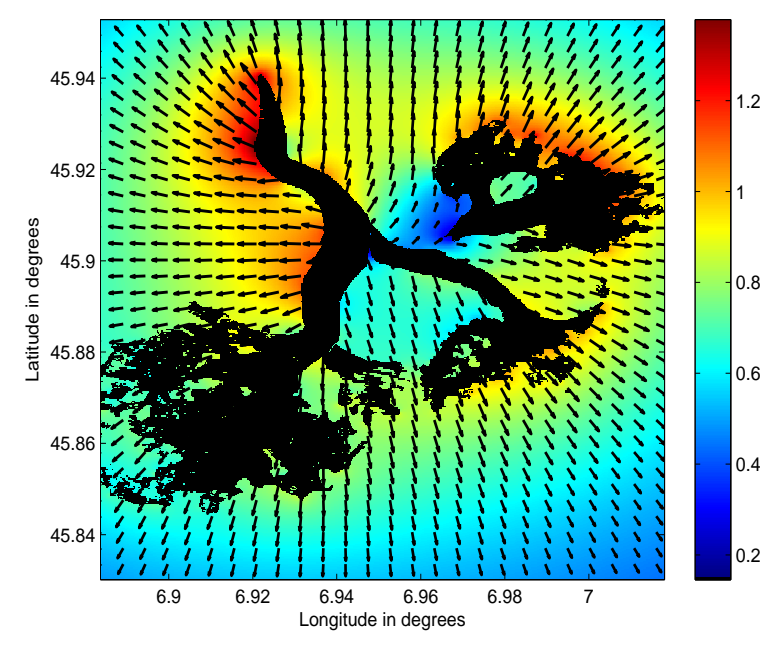

Figure 7: Horizontal displacement (in $\mathrm{mm}$ ) due to the ice thinning in the Mont Blanc area for the modified PREM. The arrows indicate the direction of the motion of the ground and the colored background shows the amplitude of the displacement. Glaciers are filled in black. 


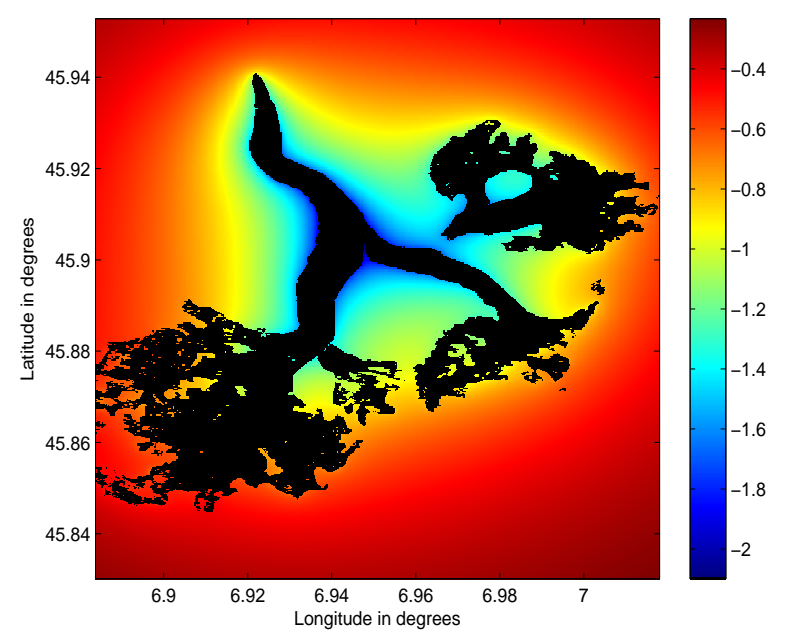

Figure 8: Elastic part of the gravity effects (in $\mu \mathrm{Gal}$ ) due to the ice thinning in the Mont Blanc area for the modified PREM. Glaciers are filled in black. 


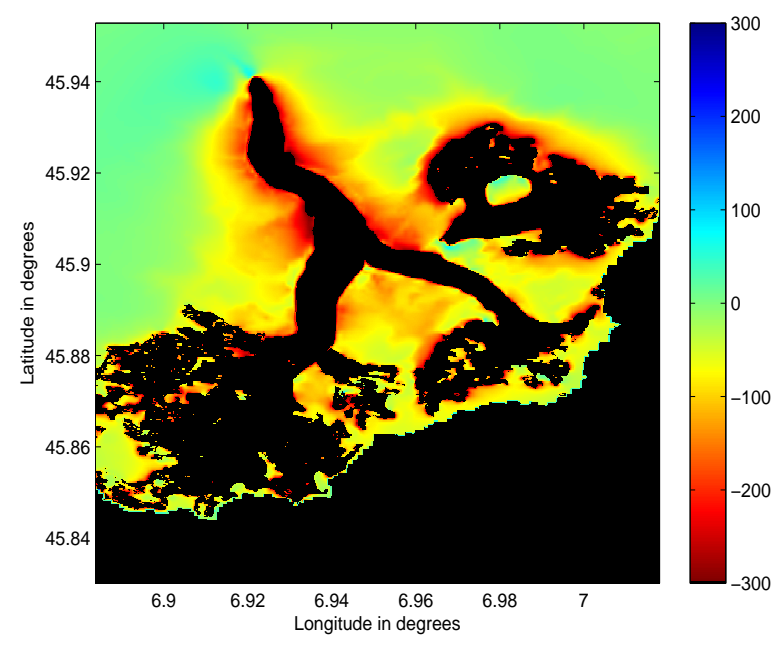

Figure 9: Newtonian part of the gravity effects (in $\mu \mathrm{Gal}$ ) due to the ice thinning in the Mont Blanc area for the modified PREM. Glaciers and the region with no topography data are filled in black. Note that the color scale is opposed to that in the former figures. 


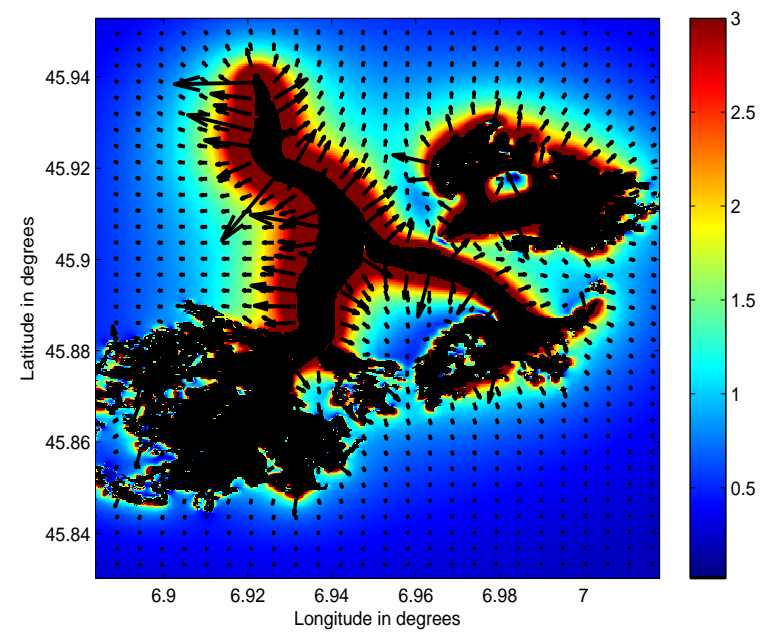

Figure 10: Tilt changes (in $\mu \mathrm{rad}$ ) due to the ice thinning in the Mont Blanc area for the modified PREM. The arrows indicate the direction of the tilt of the ground and the colored background shows the amplitude of the tilt variations. To have a clear picture of the area where the tilt is significant, we show the tilt changes up to $3 \mu \mathrm{rad}$ only. Glaciers are filled in black. 